\section{Giant Clam Shells, the Intermediate Disturbance Hypothesis, and a Big Box of Markers}

Steven N. Handel

\section{The Living World}

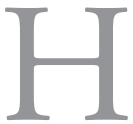

Cere comes Venus, riding in on her giant seashell. The biggest clam in the world is, of course, Tridacna gigas from the South Pacific. Why does it look like that? It's fluted, weighs hundreds of kilograms, and when alive has a fat mantle that's extruded and colored. This monster depends on symbionts, dinoflagellate algae, that live in the mantle and supplement its filter feeding with photosynthetic products. This supplementary nutrition helps explain the huge fluted shell (maximizing surface area for the algae) and the enormous size, impossible to reach by siphon generated food alone. Way to go, Venus!

It is mollusk structure and function on hyperdrive. For all members of this phylum, the shape of the shell is driven by the evolutionary pressures of living in the sea. Scallops are thin, light and have shell pleats for strength. But scallops swim through the water column; they don't burrow in the sand. Razor clams, long and thin like sabers, have vertical burrows and migrate up and down with the tide to facilitate their filter feeding. Many bivalves, such as cockles and ark shells, have deep ridges on the shells that help anchor them in the sediment, brakes against the pulling force of the tides and predators. Oysters settle on each other like a random mob of acrobats, forming reefs that facilitate their food gathering in shallow waters.

These shellfish with their complex morphology and functioning modify water quality and substrate topography and form a critical link in our coastal food webs. Even people eat them. They are so important that modern city planners are interested in reintroducing these creatures into the urban coastal world despite the insults mollusks

Ecological Restoration Vol. 31, No. 3, 2013

ISSN 1522-4740 E-ISSN 1543-4079

(C)2013 by the Board of Regents of the University of Wisconsin System.

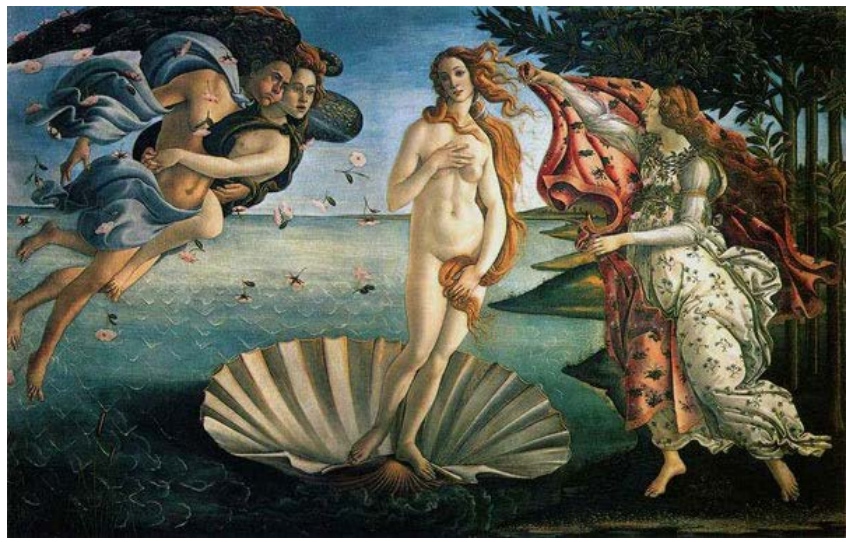

have suffered from poor water quality and overharvesting. "She sells a surfeit of seashells and soon there won't be a seashore." That should be the tongue twister.

Can this be possible? What team of workers can bring back mollusks to protect our coastal zones? What skills are needed to move forward?

\section{The Theoretical World}

There is a tight interplay between the living and abiotic components of our environment. For each organism there is checklist of physical and chemical properties that must be satisfied for a population to be initiated or to persist. The organisms are not passive residents just using their piece of the world. Their physiology and behavioral needs modify the living space, sometimes severely. Some organisms change the structure of their environment so profoundly that they are termed ecosystem engineers. Beyond changing the gas concentrations around their bodies or the membership of the living community around them, these organisms re-configure their spatial environment and create a new community trajectory. Many mollusks, including the giant clam and diminutive oyster, can act in this way. Their calcareous shells create new three-dimensional space over time modifying water flow dynamics, creating friction that slows down tidal surges, and slowing down particulate movement in the water column.

The submarine dance between mollusks and salt water never ends. The dance takes time, as the slow interplay sequentially changes the physical and chemical environment and the mollusk community expands. The dance is not always in one direction into the ecological future. Very often disturbances of different intensities and durations push the molluscan dancers back and the interplay starts anew. The timing and intensity of disturbances themselves 
act as metronomes for this dance. Lack of disturbances does not yield the richest community, as the more powerful members co-opt resources from less aggressive species. Too frequent disturbances eliminate populations before growth and reproduction allow them to persist in the area. Ecological theory, the intermediate disturbance hypothesis, has been shown in many systems. The highest biodiversity is often achieved when disturbances are neither too few nor too many. Over time, a large community of organisms can develop and cause a major structuring of the spatial world.

As urban planners look towards the natural world for components of our future infrastructure, one of the most difficult things to negotiate is the level of disturbance to create the most useful bioengineering features. In civil engineering, using steel and concrete, stasis and long-term persistence is assumed if the design is correct. With ecosystem engineering, abiotic disturbance is always around the corner, altering the living and abiotic interplay. It is change, not stasis, that is normal.

\section{The Design World}

In the studio they sit and sketch with their Photoshop and Rhino software and their big box of colored markers. What should it look like? How will it work? How does it tie in with the adjacencies? Should it be comforting or edgy or novel or challenging? Each project needs a different solution for human needs.

Every landscape designer must mesh their design theory with the possibilities and constraints of their chosen materials. The designers often use structural engineers to determine hardscape material specifications and possibilities. The materials must resist wear and tear and the physical forces of sheer, stress, and compaction. Monitoring and managing these materials is necessary for long-term persistence.

When vegetation is part of the landscape design, growth of the plants causes a changing experience, both visual and social. The functioning of the design is altered through time and with growth. This too must be stirred into the design recipe. In the marine environment, thoughts of using mollusk communities to play the role of living infrastructure must also consider growth and change over time.

\section{Braiding the Three Worlds}

Botticelli's famous image of Venus born in, and borne to us on, a giant seashell can be an analogy for civic health offered to us from the molluscan world. Oyster reefs as reported in this issue are a case study on advancing bioengineering as a remedy in a changing climate. Can invertebrate ecosystem engineers save our shores? We have urgent short-term needs to secure coastal cities from rising sea level and increasing storm surges, but the disturbance frequency seems to be rising with the tides. Meanwhile, the mollusks follow the birth and death rates of their own population dynamics. Their reef structure changes slowly over years, independent of human infrastructure requirements.

The constraints of biology may trump the wish list of city planners, as is discussed in the two commentaries that follow the shellfish reef design initiative offered in this issue. "O Oysters, come and walk with us!" wrote Lewis Carroll, now repeated by modern landscape designers, yet the walk may be a long one before reaching the desired bioengineering goal. We may find the pearl of living infrastructure in the shells of urban oysters, but when? The storms approach; ancient mollusk biology develops at its own ecological pace. 